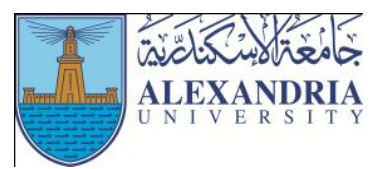

\author{
Journal of Applied Sports Science \\ August 2017, Volume 7, No. 2 \\ www.jass.alexu.edu.eg
}

\title{
Designing Excel-VBA Program for the Analysis of Force-Time Curve Profile
}

Tarek Gamal Alaaeldien ${ }^{1}$

${ }^{1}$ Assistant Professor, Faculty of Physical Education for Boys, Alexandria University, Egypt

\begin{abstract}
This paper presents a novel Excel-Visual basic for application (VBA) program that simplifies the process for sportscience students and researchers dealing with Bertec force plate form outputs, without the need for knowing any programming language or using sophisticated-expensive software programs. The designed program automatically facilitates the following tasks: starting from reading, decoding, importing, graphing, extracting, calculating, reporting and finally archiving force-time variables measured by faceplate form to an Excel spreadsheet file. The imported input variables extracted from force plate text file are: serial numbers, time, ground reaction forces in three dimension $(F x$, $F y$, $F z)$, that help in creating the calculated force-time variables in an excel report sheet including: sampling frequency, start and end time, time range of ground reaction forces in three dimensions; the maxima, minima, time and duration of both extremes, in addition to the total impulses, both positive, and negative, with their time ranges.
\end{abstract}

Keywords: Excel-VBA program, force-time curve, force plate form, spreadsheet, Dynamic chart

\section{Introduction:}

$\mathrm{T}$ he main objective of this paper is to design ExcelVisual basic for application (VBA) program that can be utilized by sport-science students and researchers for movement analysis when using Bertec force plate form outputs. Although other commercially software programs for movement analysis are available, but most of them are not affordable .In addition, they require extra costs for adding more features or updating the licensed program
(Ibrahim, 2009). Also, the commercial software may need engineering and programming background to use them (Wong \& Barford, 2010). Therefore the researcher finds that it is vital to design a free Excel-VBA software program that automatically simplifies the analysis processes. A program that can read, decode, import, graph, extract, calculate, report and archive force -time variables measured by faceplate form to an Excel spreadsheet file (Alexander \& Walkenbach, 2012; Moffat, 2011; Morgado, 2016; Reding \& Wermers, 2012; Walkenbach, 2013).

\section{Abbreviates and scientific terms}

Serial: consecutive numbers, each represents sample number starts from 0 to the last sample of data

Time: consecutive incremental time by $1 /$ force plate sampling frequency (s)

Fx: the medio-lateral component of Ground reaction force $(\mathrm{N})$

Fy: the antero-posterior component of Ground reaction force $(\mathrm{N})$

Fz: the vertical component of Ground reaction force $(\mathrm{N})$

Max: maximum value

Min: minimum value

Total impulse: is the area under force -time curve 
Total positive impulse: is the area under force- time curve when force value is positive

Total Negative impulse: is the area under force- time curve when force value is Negative

Time to reach: the time from start to reach specific event (ex. time to reach Max Fx)

Time range of $=$ the sum of the difference in time, between the start and end of specific event

Frequency $=1 /$ time difference between two consecutive faceplate time stamp

Sampling frequency is the number of samples of force data recorded per second

Area of a trapezoid: is given by (average height of a trapezoid) $\mathrm{x}$ (trapezoid base)

Trapezoid rule: an equation that uses the sum of trapezoids to represent the area under a curve (integral).

TI_Fx(total impulse in Fx): area under Fx-time curve using trapezoid rule (N.s)

SI_Fx(segmental impulse in Fx): segmental integration of Fx-time curve using trapezoid rule (N.s)

SI_pos_Fx(positive impulse in Fx): segmental integration of the area under Fx- time curve when Fx value is positive using trapezoid rule (N.s)

SI_ng_Fx(Negative impulse in Fx): segmental integration of the area under Fx- time curve when Fx value is negative using trapezoid rule (N.s)

TI_Fy(total impulse in Fy): area under Fy-time curve using trapezoid rule (N.s)

SI_Fy(segmental impulse in Fy): segmental integration of Fy-time curve using trapezoid rule (N.s)

SI_pos_Fy(positive impulse in Fy): segmental integration of the area under Fy- time curve when Fy value is positive using trapezoid rule (N.s)

SI_ng_Fy(Negative impulse in Fy): segmental integration of the area under Fy- time curve when Fy value is negative using trapezoid rule (N.s)

TI_Fz(total impulse in Fz): area under Fz-time curve using trapezoid rule (N.s)

SI_Fz(segmental impulse in Fz): segmental integration of Fz-time curve using trapezoid rule (N.s)

SI_pos_Fz(positive impulse in Fz): segmental integration of the area under Fz- time curve when Fz value is positive using trapezoid rule (N.s)

SI_ng_Fz(Negative impulse in Fz): ): segmental integration of the area under Fz- time curve when Fz value is negative using trapezoid rule (N.s)(Liengme, 2016; Mizuguchi, 2012).

\section{Methods}

In the current study Microsoft Excel 2010 along with Visual Basic for Applications version.7 are used to manipulate ground reaction forces measured by force platform (MP4060®, Bertec Corporation, Columbus, OH, USA) at a sampling rate of $1000 \mathrm{~Hz}$ during the takeoff phase of single leg horizontal jumping. The measured signals from strain gauge based force transducers are amplified, filtered, and digitized in the force plate, which minimizes signal degradation due to external noise sources during analog signal transportation. Six squash players (age: $15 \pm 0.3$ years old; height $1.50 \pm 0.15 \mathrm{~m}$; mass: $45.56 \pm 1.23 \mathrm{Kg}$ ), played in the National Egyptian team, participated in this study. The parental consent of all players was obtained and the study was approved by the institutional ethics committee of studies and researches. The data collection period started with a dynamic warmup for 10 minutes. Then, the participants were asked to stand on both legs in front of the force plate and each subject was instructed to take a step over the middle of the force plate with one foot and explosively jump as far 
forward as possible and land on the other foot . This task mimics a movement pattern which is frequently used in racket sports such as squash, badminton and fencing (Kuntze, 2010; Nadzalan et al., 2017; Phomsoupha \& Laffaye, 2015; Williams \& Kuitunen, 2010). Three trials were performed by each subject. The active rest between the three jumping trials was 4 minutes of walking. The third trial for each subject was chosen for analysis to waive the learning effect. The three ground reaction forces were measured using the force plate and saved in a text file. The vertical ground reaction force was normalized to subject body weight. Then, the designed Excel-VBA program was used to analyze force-time profile of the best horizontal jump ability of the six players.

\section{Description of Excel-VBA software program}

Excel-VBA software program has four main steps:

Step 1.Importing new data

The force plate form output file is a text file which is a different file format from Microsoft Excel 2010 workbook; therefore, it is essential to have a software program that will read, decode, and import five variables (serial, time, Fx, Fy, and Fz.) from this text file to an Excel workbook file. This will eliminate alternative complex manual approaches (Ozkaya, 1996). By clicking on the import new data control button in figure 1 , it will activate VBA module called step1_1 which calls import and name_row ranges macros as shown in Appendix 1. The import macro deletes any old raw data in sheet1 and popup a Getopenfilename dialog box to choose the imported file name as shown in figure 2 while name_row ranges macro is used to dynamically chart imported raw data forces in three dimensions versus time as shown in figure 3 .

The graphical representation of the force versus time data will help to understand the force- time profiles and will ease the selection of certain events and phases (Lim, Kim, Kim, \& Han, 2017; Torres \& Pedrini, 2016) . For example the force-time curve in the anterior-posterior direction can be used to identify the transition between braking and propulsive impulses(Marasovic, Cecic, \& Zanchi, 2009; Peterson, Neptune, \& Kautz, 2011); Subsequently, the force-time curve in the medio-lateral direction can be used to identify the transition between medial and lateral impulses (Wagner et al., 2017). In the same way, the force-time curve in the vertical direction can be used to, identify the impact peak, and the transition between negative and positive vertical impulses(Marasovic et al., 2009; Nordin, Dufek, \& Mercer, 2017).

Figure (1)

Excel-VBA program starting window

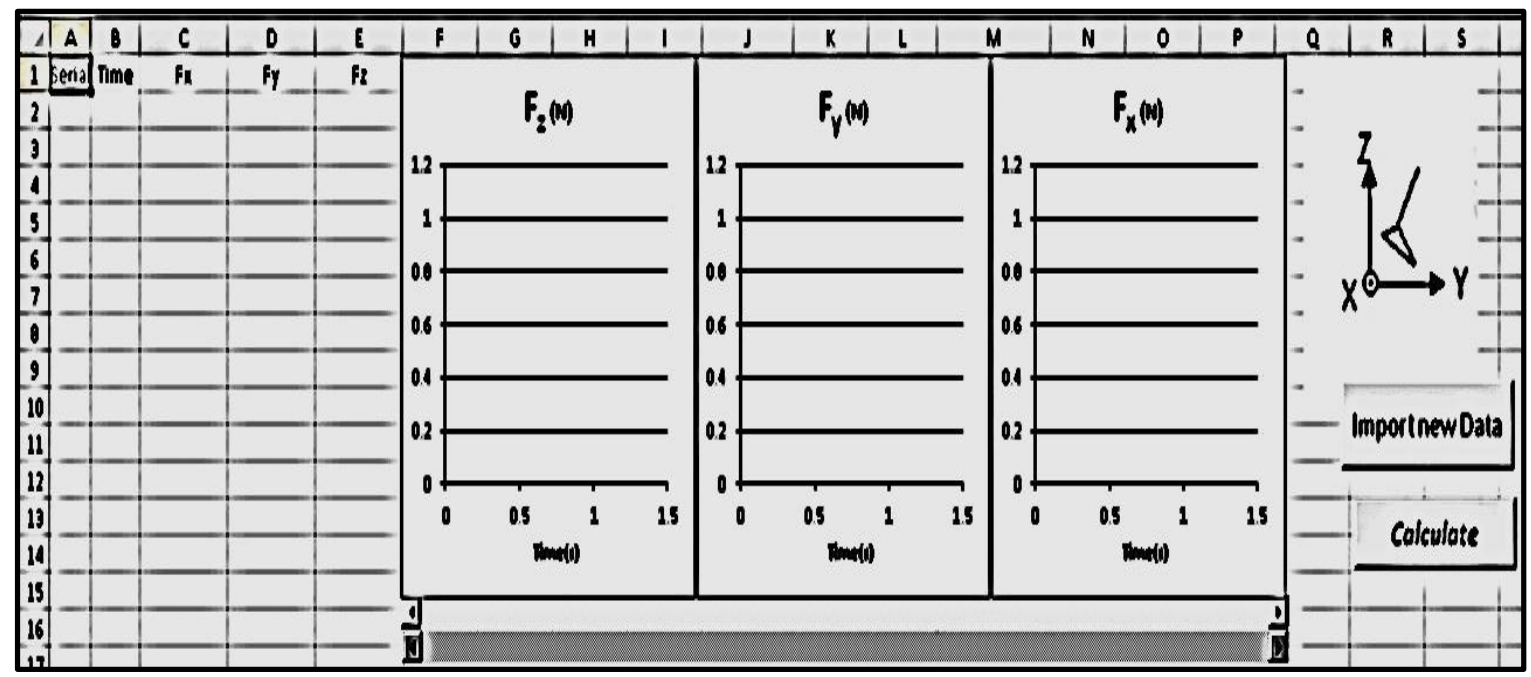


Figure (2)

Getopenfilename dialog box to choose the imported text file name

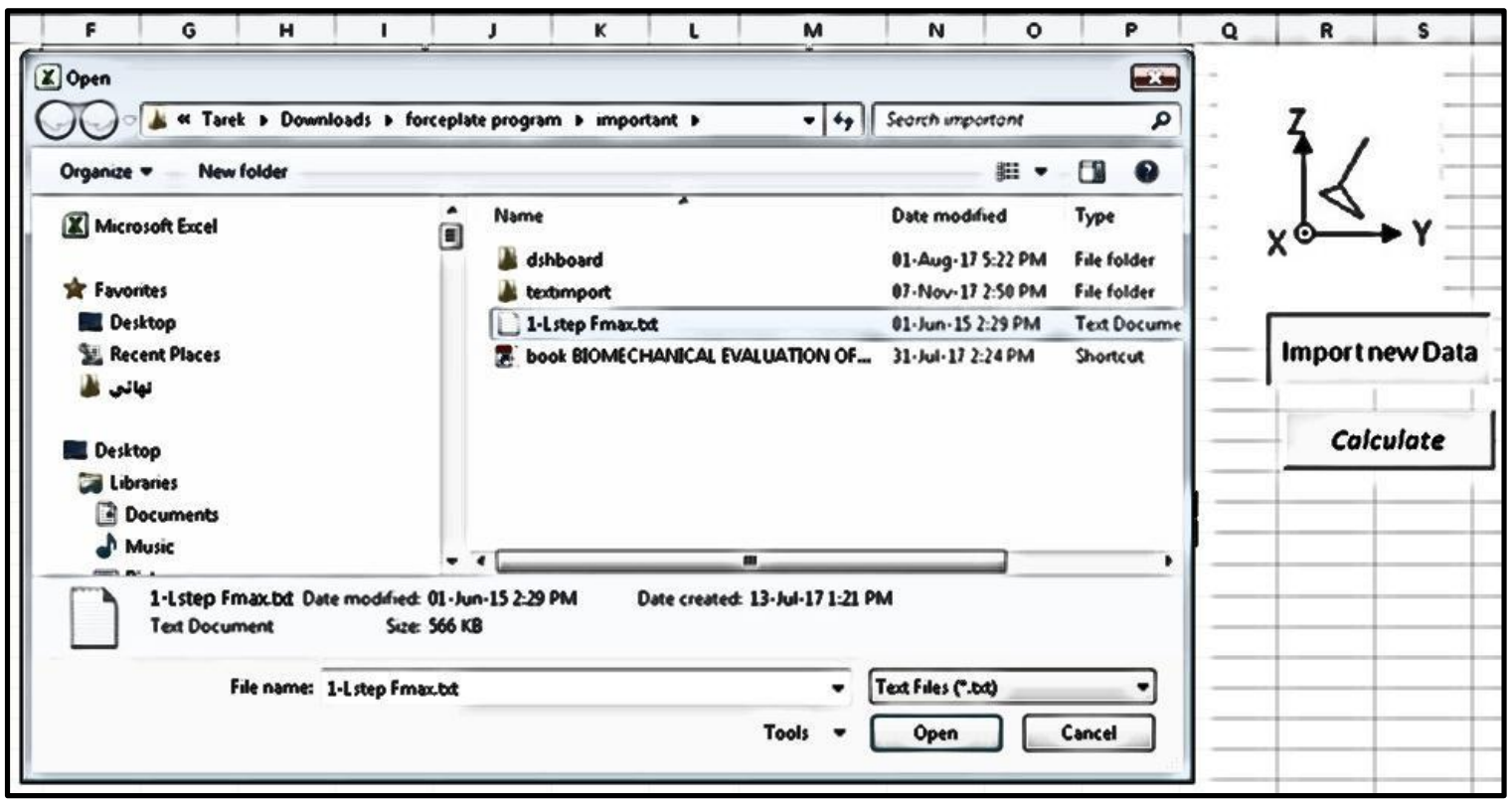

Figure (3)

Tabulated and dynamic chart representation of imported raw data

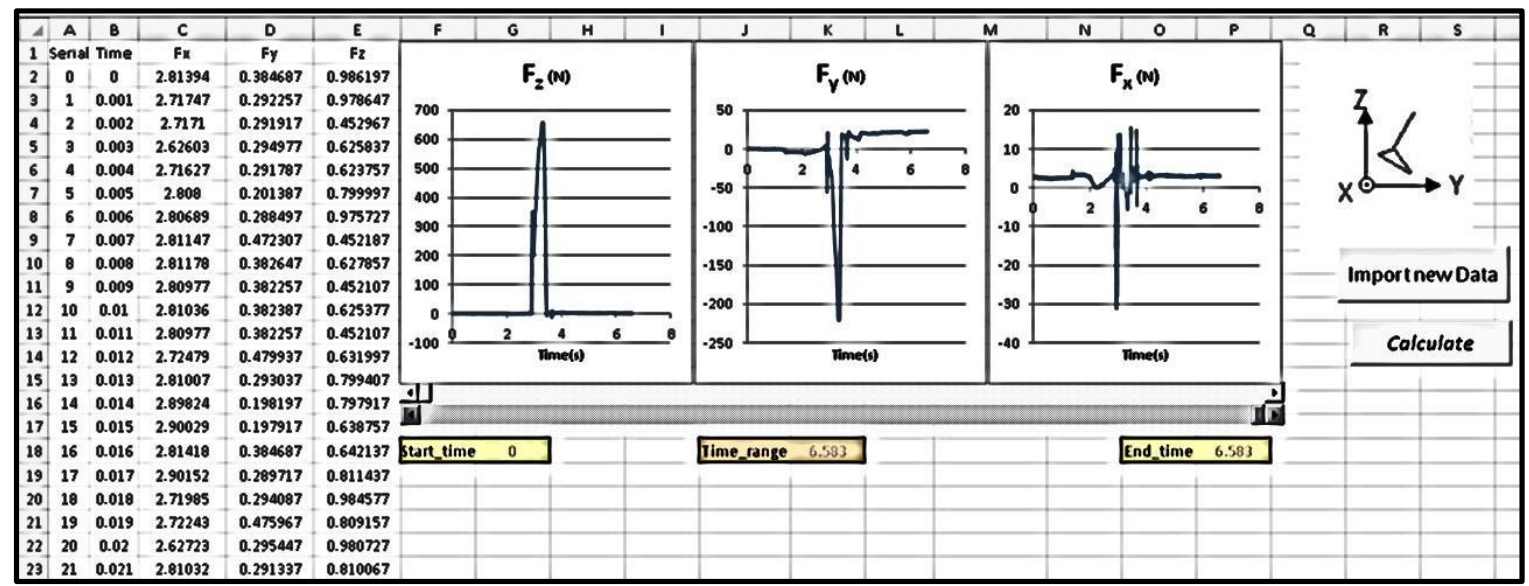

Step 2: Choosing the start and end time range for forcetime analysis

Two horizontal sliding control bars are used to define the start and end time range for force-time analysis as shown in figure 4. The upper sliding control bar defines the start, while the lower one defines the end of time range of the three synched force-time curves, in three dimensions, in the same time. In the current study, take off phase of the horizontal jump was selected as shown in figure 4 . 
Figure (4)

Choosing the start and end time range for analysis using two horizontal sliding control bars

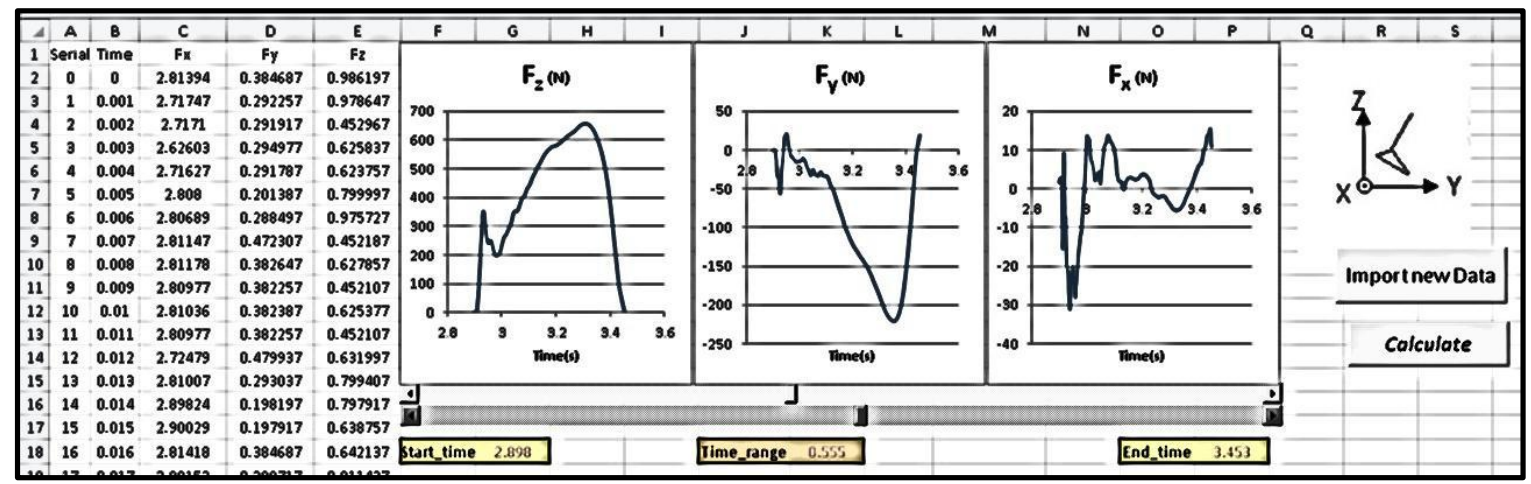

Step 3: Calculating force-time variables in sheet 2 and displaying final report in sheet3

By clicking on the Calculate control button in figure 4 , it will activate VBA module called step1_2 as shown in Appendix 1 ; This module deletes any old data in sheet2, copy selected force-time data from sheet1 to sheet2, calculate force-time variables shown in table $1 \&$ table 2 , present the final report that contains calculated force-time variables in sheet3 (Table 2) along with graphical representation of the selected force-time curves in three dimension as shown in figure (5).

Table (1)

Calculated variables in sheet 2

\begin{tabular}{|c|c|c|}
\hline $\begin{array}{c}\text { Excel } \\
\text { Column } \\
\text { naming }\end{array}$ & Variables & Calculated formulas \\
\hline $\mathbf{A}$ & Serial & \\
\hline B & Time & \\
\hline $\mathbf{C}$ & Fx(Mediolateral force) & \\
\hline D & Fy(anteroposterior force) & \\
\hline $\mathbf{E}$ & $\mathrm{Fz}$ (vertical force) & \\
\hline $\mathbf{F}$ & TI_Fx(total impulse in Fx) & $\begin{aligned} & =\operatorname{IF}(\operatorname{ROW}()=2,(\mathrm{ABS}((\$ \mathrm{~B} \$ 3-\$ \mathrm{~B} \$ 2) *(\mathrm{C} 2+\mathrm{C} 3) / 2)), \mathrm{IF}( \\
\operatorname{ROW}() & <=\operatorname{COUNT}(\mathrm{C}: \mathrm{C}),((\mathrm{F} 1)+(\mathrm{ABS}((\$ \mathrm{~B} \$ 3-\$ \mathrm{~B} \$ 2) *(\mathrm{C} 2+\mathrm{C} 3) / 2))), " '))\end{aligned}$ \\
\hline G & SI_Fx(segmental impulse in Fx) & $=\mathrm{IF}\left(\mathrm{ROW}()<=\mathrm{COUNT}(\mathrm{C}: \mathrm{C}), \mathrm{ABS}\left((\$ \mathrm{~B} \$ 3-\$ \mathrm{~B} \$ 2)^{*}(\mathrm{C} 2+\mathrm{C} 3) / 2\right), " '\right)$ \\
\hline $\mathbf{H}$ & SI_pos_Fx(positive impulse in Fx) & $=\mathrm{IF}\left(\mathrm{AND}(\mathrm{C} 2>=0, \mathrm{ROW}()<=\mathrm{COUNT}(\mathrm{C}: \mathrm{C})), \mathrm{G} 2, "{ }^{\prime}\right)$ \\
\hline $\mathbf{I}$ & SI_ng_Fx(Negative impulse in Fx) & $=\mathrm{IF}\left(\mathrm{AND}(\mathrm{C} 2<=0, \mathrm{ROW}()<=\mathrm{COUNT}(\mathrm{C}: \mathrm{C})), \mathrm{G} 2, "{ }^{\prime}\right)$ \\
\hline $\mathbf{J}$ & TI_Fy(total impulse in Fy) & $\begin{aligned} & =\mathrm{IF}(\mathrm{ROW}()=2,(\mathrm{ABS}((\$ \mathrm{~B} \$ 3-\$ \mathrm{~B} \$ 2) *(\mathrm{D} 2+\mathrm{D} 3) / 2)), \mathrm{IF}( \\
\mathrm{ROW}() & \left.\left.<=\mathrm{COUNT}(\mathrm{D}: \mathrm{D}),((\mathrm{J} 1)+(\mathrm{ABS}((\$ \mathrm{~B} \$ 3-\$ \mathrm{~B} \$ 2) *(\mathrm{D} 2+\mathrm{D} 3) / 2))), "{ }^{\prime}\right)\right)\end{aligned}$ \\
\hline $\mathbf{K}$ & SI_Fy(segmental impulse in Fy) & $=\mathrm{IF}\left(\mathrm{ROW}()<=\mathrm{COUNT}(\mathrm{D}: \mathrm{D}), \mathrm{ABS}\left((\$ \mathrm{~B} \$ 3-\$ \mathrm{~B} \$ 2)^{*}(\mathrm{D} 2+\mathrm{D} 3) / 2\right), " "\right)$ \\
\hline $\mathbf{L}$ & SI_pos_Fy(positive impulse in Fy) & $=\mathrm{IF}\left(\mathrm{AND}(\mathrm{D} 2>=0, \mathrm{ROW}()<=\mathrm{COUNT}(\mathrm{D}: \mathrm{D})), \mathrm{K} 2, "{ }^{\prime}\right)$ \\
\hline $\mathbf{M}$ & SI_ng_Fy(Negative impulse in Fy) & $=\mathrm{IF}(\mathrm{AND}(\mathrm{D} 2<=0, \mathrm{ROW}()<=\mathrm{COUNT}(\mathrm{D}: \mathrm{D})), \mathrm{K} 2, " ")$ \\
\hline $\mathbf{N}$ & TI_Fz(total impulse in Fz) & $\begin{aligned} & =\mathrm{IF}(\operatorname{ROW}()=2,(\mathrm{ABS}((\$ \mathrm{~B} \$ 3-\$ \mathrm{~B} \$ 2) *(\mathrm{E} 2+\mathrm{E} 3) / 2)), \mathrm{IF}( \\
\operatorname{ROW}() & \left.\left.<=\operatorname{COUNT}(\mathrm{E}: \mathrm{E}),((\mathrm{N} 1)+(\mathrm{ABS}((\$ \mathrm{~B} \$ 3-\$ \mathrm{~B} \$ 2) *(\mathrm{E} 2+\mathrm{E} 3) / 2))),{ }^{\prime \prime}\right)\right)\end{aligned}$ \\
\hline $\mathbf{O}$ & SI_Fz(segmental impulse in Fz) & $=\mathrm{IF}\left(\mathrm{ROW}()<=\mathrm{COUNT}(\mathrm{E}: \mathrm{E}), \mathrm{ABS}\left((\$ \mathrm{~B} \$ 3-\$ \mathrm{~B} \$ 2)^{*}(\mathrm{E} 2+\mathrm{E} 3) / 2\right), " "\right)$ \\
\hline $\mathbf{P}$ & SI_pos_Fz(positive impulse in Fz) & $=\mathrm{IF}(\mathrm{AND}(\mathrm{E} 2>=0, \mathrm{ROW}()<=\mathrm{COUNT}(\mathrm{E}: \mathrm{E})), \mathrm{O} 2, " ")$ \\
\hline $\mathbf{Q}$ & SI_ng_Fz(Negative impulse in Fz) & $=\mathrm{IF}(\mathrm{AND}(\mathrm{E} 2<=0, \mathrm{ROW}()<=\mathrm{COUNT}(\mathrm{E}: \mathrm{E})), \mathrm{O} 2, " ")$ \\
\hline
\end{tabular}


Table (2)

Calculated variables and their formulas in sheet 3 (final report)

\begin{tabular}{|c|c|}
\hline Calculated variables & Calculated formulas \\
\hline $\operatorname{Max} F x$ & $=$ MAX $($ sheet $2 ! \$ C: \$ C)$ \\
\hline $\operatorname{Min} \mathbf{F x}$ & $=\mathrm{MIN}($ sheet $2 ! \$ C: \$ C)$ \\
\hline Max Fy & $=\mathrm{MAX}($ sheet $2 ! \$ \mathrm{D}: \$ \mathrm{D})$ \\
\hline Min Fy & $=\mathrm{MIN}($ sheet $2 ! \$ \mathrm{D}: \$ \mathrm{D})$ \\
\hline $\operatorname{Max} \mathbf{F z}$ & $=$ MAX $($ sheet $2 ! \$ E: \$ E)$ \\
\hline $\operatorname{Min} \mathbf{F z}$ & $=\mathrm{MIN}($ sheet $2 ! \$ \mathrm{E}: \$ \mathrm{E})$ \\
\hline Total Impulse Fx & $=$ MAX $($ sheet $2 ! \$ F: \$ F)$ \\
\hline Total Postive Impulse Fx & $=\mathrm{SUM}($ sheet $2 ! \$ \mathrm{H}: \$ \mathrm{H})$ \\
\hline Total Negative Impulse Fx & $=$ SUM $($ sheet $2 ! \$ I: \$ I)$ \\
\hline Total Impulse Fy & $=\mathrm{MAX}($ sheet $2 ! \$ \mathrm{~J}: \$ \mathrm{~J})$ \\
\hline Total Postive Impulse Fy & $=\mathrm{SUM}($ sheet $2 ! \$ \mathrm{~L}: \$ \mathrm{~L})$ \\
\hline Total Negative Impulse Fy & $=$ SUM $($ sheet $2 ! \$ M: \$ M)$ \\
\hline Total Impulse Fz & $=\mathrm{MAX}($ sheet $2 ! \$ \mathrm{~N}: \$ \mathrm{~N})$ \\
\hline Total Postive Impulse Fz & $=\mathrm{SUM}($ sheet $2 \mathrm{IP}: \$ \mathrm{P})$ \\
\hline Total Negative Impulse Fz & $=\mathrm{SUM}($ sheet $2 ! \$ \mathrm{Q}: \$ \mathrm{Q})$ \\
\hline Frequency & $=$ sheet $2 ! \$ B \$ 3$-sheet $2 ! \$ B \$ 2$ \\
\hline start time & $=$ sheet $2 ! \$ B \$ 2$ \\
\hline end time & $=\mathrm{MAX}($ sheet $2 ! \$ \mathrm{~B}: \$ \mathrm{~B})$ \\
\hline time range(end time - start time) & $=\mathrm{MAX}($ sheet $2 ! \$ \mathrm{~B}: \$ \mathrm{~B})$-sheet $2 ! \$ \mathrm{~B} \$ 2$ \\
\hline Time of Max Fx & $=\mathrm{INDEX}($ sheet $2 ! \$ \mathrm{~B}: \$ \mathrm{~B}, \mathrm{MATCH}(\mathrm{MAX}($ sheet $2 ! \$ \mathrm{C}: \$ \mathrm{C})$, sheet $2 ! \$ \mathrm{C}: \$ \mathrm{C}, 0))$ \\
\hline Time of Min Fx & $=\mathrm{INDEX}($ sheet $2 ! \$ \mathrm{~B}: \$ \mathrm{~B}, \mathrm{MATCH}(\mathrm{MIN}($ sheet $2 ! \$ \mathrm{C}: \$ \mathrm{C})$,sheet 2 \$C: $\$ \mathrm{C}, 0))$ \\
\hline Time of Max Fy & $=\mathrm{INDEX}($ sheet $2 ! \$ \mathrm{~B}: \$ \mathrm{~B}, \mathrm{MATCH}(\mathrm{MAX}($ sheet $2 ! \$ \mathrm{D}: \$ \mathrm{D})$, sheet $2 ! \$ \mathrm{D}: \$ \mathrm{D}, 0))$ \\
\hline Time of Min Fy & $=\mathrm{INDEX}($ sheet $2 ! \$ \mathrm{~B}: \$ \mathrm{~B}, \mathrm{MATCH}(\mathrm{MIN}($ sheet $2 ! \$ \mathrm{D}: \$ \mathrm{D})$, sheet $2 ! \mathrm{D}: \$ \mathrm{D}, 0))$ \\
\hline Time of Max Fz & $=\mathrm{INDEX}($ sheet2!\$B:\$B,MATCH $(\mathrm{MAX}($ sheet $2 ! \$ E: \$ E)$,sheet $2 ! \$ E: \$ E, 0))$ \\
\hline Time of Min Fz & $=\operatorname{INDEX}($ sheet2!\$B:\$B,MATCH$(\mathrm{MIN}($ sheet2!\$E:\$E),sheet2!\$E:\$E,0)) \\
\hline Time to reach Max Fx & $=\operatorname{INDEX}($ sheet $2 ! \$ B: \$ B, M A T C H(M A X($ sheet $2 ! \$ C: \$ C)$, sheet $2 ! \$ C: \$ C, 0))$-sheet $2 ! \$ B \$ 2$ \\
\hline Time to reach $\operatorname{Min} \mathbf{F x}$ & $=\operatorname{INDEX}($ sheet $2 ! \$ B: \$ B, M A T C H(M I N($ sheet $2 ! \$ C: \$ C)$,sheet $2 ! \$ C: \$ C, 0))$-sheet 2 \$B $\$ 2$ \\
\hline Time to reach Max Fy & $=\operatorname{INDEX}($ sheet $2 ! \$ B: \$ B, M A T C H(M A X($ sheet $2 ! \$ D: \$ D)$,sheet $2 ! \$ D: \$ D, 0))$-sheet $2 ! \$ B \$ 2$ \\
\hline Time to reach Min Fy & $=\operatorname{INDEX}($ sheet $2 ! \$ B: \$ B, M A T C H(M I N($ sheet $2 ! \$ D: \$ D)$, sheet $2 ! \$ D: \$ D, 0))$-sheet $2 ! \$ B \$ 2$ \\
\hline Time to reach Max Fz & $=\operatorname{INDEX}($ sheet $2 ! \$ B: \$ B, M A T C H(M A X($ sheet $2 ! \$ E: \$ E)$,sheet $2 ! \$ E: \$ E, 0))$-sheet $2 ! \$ B \$ 2$ \\
\hline Time to reach Min $\mathbf{F z}$ & $=\mathrm{INDEX}($ sheet $2 ! \$ \mathrm{~B}: \$ \mathrm{~B}, \mathrm{MATCH}(\mathrm{MIN}($ sheet $2 ! \$ \mathrm{E}: \$ \mathrm{E})$,sheet $2 ! \$ \mathrm{E}: \$ \mathrm{E}, 0))$-sheet $2 ! \$ \mathrm{~B} \$ 2$ \\
\hline Time range of Total Impulse Fx & $=$ COUNT $($ sheet $2 ! \$ G: \$ G) *($ sheet $2 ! \$ B \$ 3-$ sheet $2 ! \$ B \$ 2)$ \\
\hline Total Postive Impulse Fx & $=\mathrm{COUNT}($ sheet $2 ! \$ \mathrm{H}: \$ \mathrm{H}) *($ sheet $2 ! \$ \mathrm{~B} \$ 3-$ sheet $2 ! \$ \mathrm{~B} \$ 2)$ \\
\hline Time range of Total Negative Impulse Fx & $=$ COUNT $($ sheet $2 ! \$ I: \$ I) *($ sheet $2 ! \$ B \$ 3-$ sheet $2 ! \$ B \$ 2)$ \\
\hline Time range of Total Impulse Fy & $=\mathrm{COUNT}($ sheet $2 ! \$ \mathrm{~K}: \$ \mathrm{~K}) *($ sheet $2 ! \$ \mathrm{~B} \$ 3$-sheet $2 ! \$ \mathrm{~B} \$ 2)$ \\
\hline Time range of Total Postive Impulse Fy & $=$ COUNT $($ sheet $2 ! \$ \mathrm{~L}: \$ \mathrm{~L}) *($ sheet $2 ! \$ \mathrm{~B} \$ 3-$ sheet $2 ! \$ \mathrm{~B} \$ 2)$ \\
\hline Time range of Total Negative Impulse Fy & $=$ COUNT $($ sheet $2 ! \$ M: \$ M) *($ sheet $2 ! \$ B \$ 3-$ sheet $2 ! \$ B \$ 2)$ \\
\hline Time range of Total Impulse $\mathbf{F z}$ & $=\mathrm{COUNT}($ sheet $2 ! \$ \mathrm{O}: \$ \mathrm{O}) *($ sheet $2 ! \$ \mathrm{~B} \$ 3$-sheet $2 ! \$ \mathrm{~B} \$ 2)$ \\
\hline Time range of Total Postive Impulse Fz & $=$ COUNT $($ sheet $2 ! \$ \mathrm{P}: \$ \mathrm{P}) *($ sheet $2 ! \$ \mathrm{~B} \$ 3-$ sheet $2 ! \$ \mathrm{~B} \$ 2)$ \\
\hline Time range of Total Negative Impulse Fz & $=\mathrm{COUNT}($ sheet $2 ! \$ \mathrm{Q}: \$ \mathrm{Q}) *($ sheet $2 ! \$ \mathrm{~B} \$ 3-$ sheet $2 ! \$ \mathrm{~B} \$ 2)$ \\
\hline
\end{tabular}


Figure (5)

Final Report.

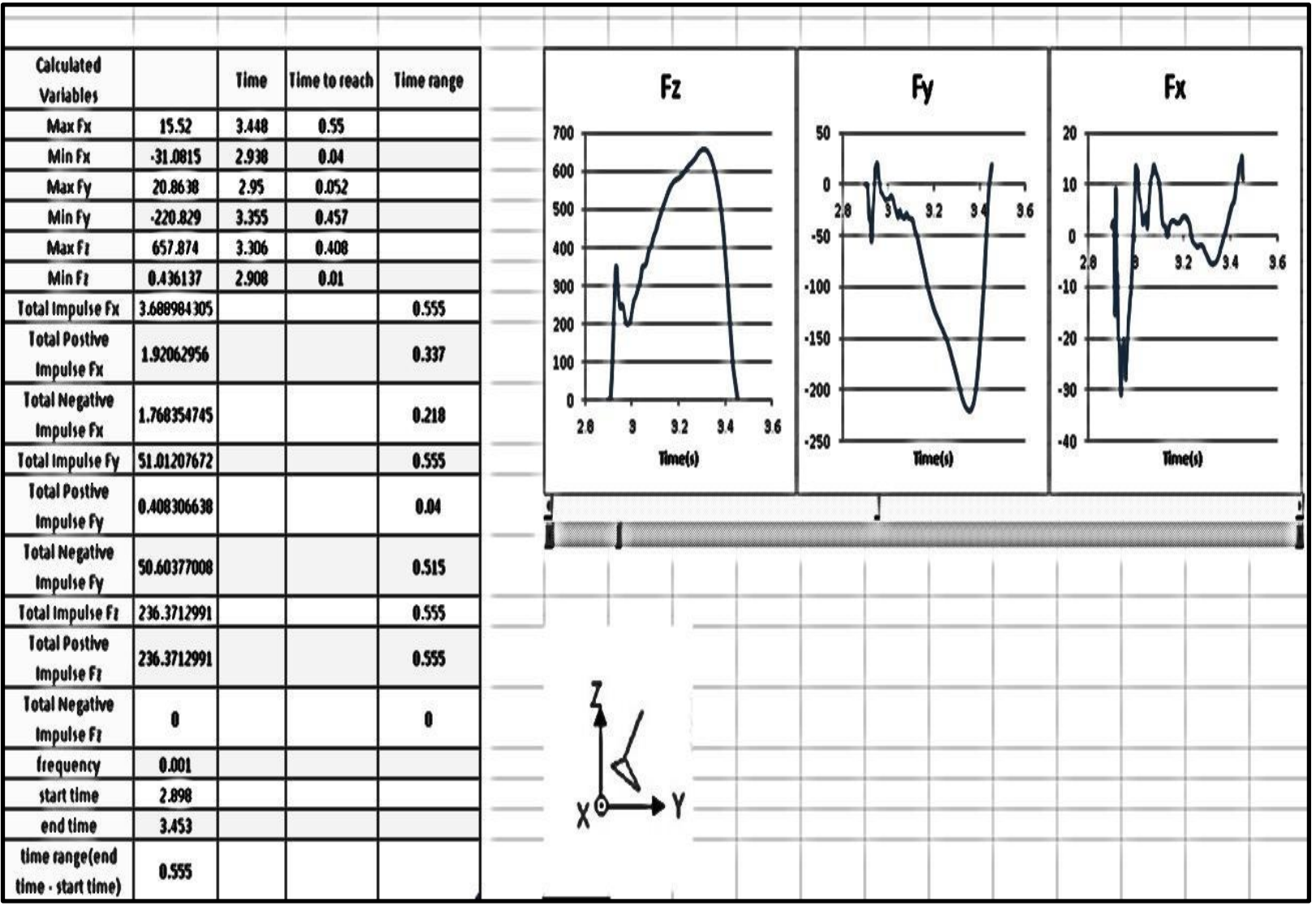

Step 4: saving all the workbook sheets as a workbook file for further analysis.

All workbook sheets are saved by clicking file save as button from the main menu and naming the workbook with a special name (subject name_ trial number). The saved files can be used to compare between different trials and subjects.

\section{Conclusion}

The Excel-VBA program provides the capability to rapidly, and automatically- without the need for knowledge of programming language or using any sophisticated-expensive software- to read, decode, import, graph, extract, calculate, report and archive force -time variables measured by force platform to an Excel spreadsheet file.

The main limitation of this study was that the program is designed for interfacing with force platform (MP4060®, Bertec Corporation, Columbus, OH, USA). Further studies need to be done using another type of force plate such as commonly used AMTI force plate.

\section{References}

1- Alexander, M. T., \& Walkenbach, J. (2012). 101 readyto-use Excel macros. from http://site.ebrary.com/id/10575527

2- Ibrahim, D. (2009). Using the excel spreadsheet in teaching science subjects. Procedia - Social and Behavioral Sciences, 1(1), 309-312. doi: 10.1016/j.sbspro.2009.01.058

3- Kuntze, G., Mansfield, Neil J., \& Sellers, William. (2010). A biomechanical analysis of common lunge tasks in badminton. (Journal), 183-191.

4- Liengme, B. V. (2016). Excel VBA for physicists a primer. from http://iopscience.iop.org/book/978-1-68174461-2

5- Lim, D.-H., Kim, W.-S., Kim, H.-J., \& Han, C.-S. (2017). Development of real-time gait phase detection system for a lower extremity exoskeleton robot. International Journal of Precision Engineering and 
Manufacturing, 18(5), 681-687. doi: 10.1007/s12541-0170081-9

6- Marasovic, T., Cecic, M., \& Zanchi, V. (2009). Analysis and interpretation of ground reaction forces in normal gait. WSEAS Trans. Syst. WSEAS Transactions on Systems, 8(9), 1105-1114.

7- Mizuguchi, S. (2012). Net Impulse and Net Impulse Characteristics in Vertical Jumping. from http://etdsubmit.etsu.edu/etd/theses/available/etd-0625112-140839/

8- Moffat, S. (2011). Excel 2010 advanced. London: BookBoon.

9- Morgado, F. (2016). Programming Excel with VBA : a practical real-world guide. from http://www.books24x7.com/marc.asp?bookid=119908

10- Nadzalan, A., Mohamad, N., Lee, J., Tan, K., Janep, M., \& Chinnasee, C. (2017). Muscle Activation Analysis of Step and Jump Forward Lunge among Badminton Players. Journal of Engineering and Science Research, 1(2), 60-65. doi: 10.26666/rmp.jesr.2017.2.11

11- Nordin, A. D., Dufek, J. S., \& Mercer, J. A. (2017). Three-dimensional impact kinetics with foot-strike manipulations during running. JSHS Journal of Sport and Health Science, 6(4), 489-497.

12- Ozkaya, S. I. (1996). An EXCEL macro for importing $\log$ ASCII standard (LAS) files into EXCEL worksheets. Computers \& geosciences., 22(1), 75.

13- Peterson, C. L., Neptune, R. R., \& Kautz, S. A. (2011). Braking and propulsive impulses increase with speed during accelerated and decelerated walking. Gait Posture Gait and Posture, 33(4), 562-567.

14- Phomsoupha, M., \& Laffaye, G. (2015). The Science of Badminton: Game Characteristics, Anthropometry, Physiology, Visual Fitness and Biomechanics. Sports Med Sports Medicine, 45(4), 473-495.

15- Reding, E. E., \& Wermers, L. (2012). Microsoft Excel 2010 for medical professionals. Boston: Course Technology/Cengage Learning.

16- Torres, B. S., \& Pedrini, H. (2016). Detection of complex video events through visual rhythm. The Visual Computer. doi: 10.1007/s00371-016-1321-1

17- Wagner, M., Slijepcevic, D., Horsak, B., Rind, A., Zeppelzauer, M., \& Aigner, W. (2017). KAVAGait: Knowledge-assisted visual analytics for clinical gait analysis. arXiv preprint arXiv:1707.06105.

18- Walkenbach, J. (2013). Excel 2010 power programming with vba. from http://public.eblib.com/choice/publicfullrecord.aspx? $\mathrm{p}=40$ 27857

19- Williams, B., \& Kuitunen, S. (2010). LUNGE FORCES AND TECHNIQUE OF JUNIOR SQUASH PLAYERS. ISBS-Conference Proceedings Archive.

20- Wong, K. W. W., \& Barford, J. P. (2010). Teaching Excel VBA as a problem solving tool for chemical engineering core courses. Education for Chemical Engineers, 5(4), e72-e77. doi: 10.1016/j.ece.2010.07.002 